\title{
Influence of Low-temperature Heat Treatment after Deformation on Hydrogen Entry into Steel Sheets
}

\author{
Yuki TOJI, ${ }^{1)}$ Shusaku TAKAGI, ${ }^{2)}$ Kohei HASEGAWA ${ }^{1)}$ and Kazuhiro SETO ${ }^{2)}$ \\ 1) Steel Research Laboratory, JFE Steel Corporation, 1 Kokan-cho, Fukuyama, Hiroshima, 721-8510 Japan. \\ 2) Steel Research Laboratory, JFE Steel Corporation, 1 Kawasaki-cho, Chuo-ku, Chiba, 260-0835 Japan.
}

(Received on June 30, 2011; accepted on July 27, 2011)

\begin{abstract}
To ensure safety against delayed fracture caused by hydrogen embrittlement under service environments of steel sheets for auto body parts used after forming and paint baking, it is quite important to understand hydrogen entry into steels under the service environments, which could be influenced by part processing parameters such as forming and the following paint baking conditions. In this study, the influence of temperature and holding time in low-temperature heat treatment after deformation on hydrogen entry into steel sheets was investigated in detail, and the mechanism of the decrement of hydrogen entry due to the heat treatment was discussed using $0.2 \% \mathrm{C}$ steel, $0.002 \% \mathrm{C}$ steel and IF steel. The steels were $10-20 \%$ cold rolled to introduce plastic strain, then heat-treated at $50-170^{\circ} \mathrm{C}$ for $0.2-20160 \mathrm{~min}$, followed by immersion in $\mathrm{pH} 1-\mathrm{HCl}$ for at most $72 \mathrm{~h}$ to introduce hydrogen into the steels. Hydrogen entry into the steels during immersion in $\mathrm{pH} 1-\mathrm{HCl}$ increased with the cold rolling and decreased with the following lowtemperature heat treatment, and as the heating temperature and holding time increased, hydrogen entry during immersion in $\mathrm{HCl}$ decreased. This indicates hydrogen trapping sites, which were introduced by the cold rolling, decreased due to the low-temperature heat treatment. From a comparison of steels with and without solute carbon atoms, the decrement of hydrogen trapping sites due to the low-temperature heat treatment was attributed to both the decrement of vacancies and occupation of hydrogen trapping sites around dislocations by interstitial solute atoms such as carbon.
\end{abstract}

KEY WORDS: hydrogen entry; hydrogen uptake; hydrogen embrittlement; delayed fracture; plastic strain; $\mathrm{BH}$ treatment; bake-hardening treatment; heat treatment; vacancy; dislocation; solute carbon; high strength steel sheet.

\section{Introduction}

The automotive industry has a great increasing demand to improve fuel efficiency and passive safety of vehicles. In order to achieve both requirements, down-gauged high strength steels are applied to reduce weight and to improve crashworthiness of car bodies. In particular, ultra-high strength steel sheets with tensile strengths (TS) of 1180 $\mathrm{MPa}$ or higher have been applied to parts around the cabin that protect the passengers. ${ }^{1,2)}$ However, steels with TS of $1180 \mathrm{MPa}$ grade or higher are generally susceptible to delayed fracture caused by hydrogen embrittlement under service environments. ${ }^{3)}$

Steel sheets for automobiles are usually formed into various parts by cold working. Therefore, plastic strain introduced by cold working must be considered as a factor affecting hydrogen embrittlement, ${ }^{4,5)}$ in addition to applied stress and content of diffusible hydrogen entering steels, which are considered as factors in high strength steel bolts. ${ }^{3,6-8)}$ It is also known that hydrogen entry into steels increases with plastic strain, ${ }^{9)}$ and the amount of hydrogen entry was reported to show a close correlation with equivalent strain introduced into steels. ${ }^{10)}$

Automotive steel sheets are also usually heated to around $170^{\circ} \mathrm{C}$ in the paint baking process after forming. This heat treatment after forming is well known as bake-hardening (BH) treatment that affects the mechanical properties of steels. However, there are few studies concerning the influence of low-temperature heat treatment such as BH treatment after cold working on hydrogen entry into steels. Nagumo et al..$^{9)}$ reported that hydrogen entry into a medium carbon martensitic steel $(0.3 \% \mathrm{C}-1.5 \% \mathrm{Mn}-0.5 \% \mathrm{Cr}-0.5 \% \mathrm{Mo}$ steel) under a cathodic charging condition increased with $2 \%$ strain and decreased with a heat treatment at $250^{\circ} \mathrm{C}$ for $1 \mathrm{~h}$ after $2 \%$ straining. The decrement of hydrogen entry was considered to be caused by the decrement of vacancies, which were introduced by the straining, during the heat treatment.

Understanding of such phenomena, which hydrogen entry is influenced by plastic strain and the following heat treatment, is important for ensuring safety against delayed fracture under service environments of steel sheets used after forming and paint baking. However, there have been no detailed reports concerning the effects of heating temperature and holding time in the low-temperature heat treatment after deformation on hydrogen entry.

In this study, the influences of temperature and holding time in the low-temperature heat treatment after deformation on hydrogen entry into steel sheets were investigated in detail. 
Furthermore, the mechanism of the decrement of hydrogen entry due to the heat treatment after deformation was discussed.

\section{Experimental Procedure}

\subsection{Effect of Heat Treatment on Hydrogen Entry in $0.2 \%$ C Martensitic Steel}

A $0.2 \% \mathrm{C}$ steel was used to investigate the effect of heat treatment on hydrogen entry in a general ultra-high strength martensitic steel. The chemical composition of the steel is listed in Table 1. The steel was prepared by vacuum induction melting. The ingot was hot rolled followed by cold rolling to sheet with a thickness of $1.6 \mathrm{~mm}$. The sheet was austenitized at $900^{\circ} \mathrm{C}$ for $30 \mathrm{~min}$, then water quenched, followed by tempering at $200^{\circ} \mathrm{C}$ for $30 \mathrm{~min}$. This steel is referred to as the tempered steel in the following. Table 2 shows the tensile properties of the tempered steel. The tensile strength of the steel was $1501 \mathrm{MPa}$. Figure 1 shows an SEM image of the microstructure of the tempered steel. The steel had a fully tempered martensitic microstructure.

Instead of forming as in the manufacturing process for auto body parts, the tempered steel was $10 \%$ cold rolled to introduce plastic strain. The $10 \%$ cold-rolled steel was then heattreated at $50-170^{\circ} \mathrm{C}$ for $0.3-10800 \mathrm{~min}$. The tempered steel, the $10 \%$ cold-rolled steel and the heat-treated steels were immersed into $\mathrm{pH} 1-\mathrm{HCl}$ for at most $72 \mathrm{~h}$ in order to introduce hydrogen into the steels. The cold-rolled steel and the heattreated steels were kept in a freezer until the immersion in $\mathrm{HCl}$ to avoid the recovery of defects introduced by the cold rolling during holding at room temperature. The contents of hydrogen that entered the steels were measured by thermal desorption analysis (TDA) using gas chromatography. The heating rate was normally $200^{\circ} \mathrm{C} / \mathrm{h}$ and the sampling interval was $5 \mathrm{~min}$. In this study, the integration of the first evolution peak (under about $200^{\circ} \mathrm{C}$ ) was defined as the diffusible hydrogen content. For some specimens, the dislocation density was measured by the X-ray diffraction method. ${ }^{11,12)}$

Table 1. Chemical composition of steel used (mass\%).

\begin{tabular}{ccccccccc}
\hline Steel & $\mathrm{C}$ & $\mathrm{Si}$ & $\mathrm{Mn}$ & $\mathrm{P}$ & $\mathrm{S}$ & $\mathrm{Al}$ & $\mathrm{N}$ & $\mathrm{Fe}$ \\
\hline $\mathrm{A}$ & 0.198 & 0.01 & 1.76 & 0.009 & 0.0007 & 0.029 & 0.0029 & Bal. \\
\hline
\end{tabular}

Table 2. Tensile properties of steel A.

\begin{tabular}{ccc}
\hline YS (MPa) & TS (MPa) & El (\%) \\
\hline 1226 & 1501 & 7.7 \\
\hline
\end{tabular}

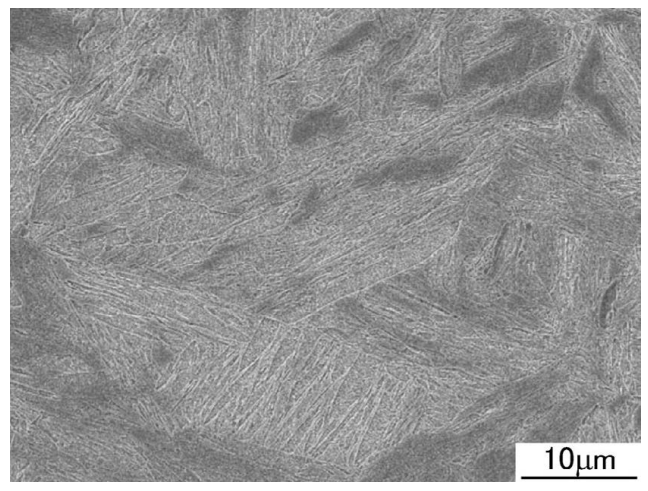

Fig. 1. SEM microstructure of steel A.

\subsection{Influence of Solute Carbon Content on Hydrogen Entry}

In order to clarify the mechanism of the decrement of hydrogen entry into deformed steel by low-temperature heat treatment, the influence of solute carbon content, which may affect the interaction between hydrogen atoms and defects, on hydrogen entry was investigated using low carbon and ultra-low carbon steels in the discussion section. The chemical compositions of these steels are listed in Table 3. The Ti contents were changed to vary the solute carbon contents. The steels were prepared by vacuum induction melting. The ingots were hot rolled followed by cold rolling to sheets with a thickness of $1.6 \mathrm{~mm}$. The sheets were then annealed at $800^{\circ} \mathrm{C}$ for $150 \mathrm{~s}$ followed by air-cooling to room temperature. These steels are referred to as the annealed steels in the following. Table 4 shows the tensile properties of the annealed steels. UYS and LYS expresses the upper yield stress and lower yield stress, respectively. AI, the aging index, which is an index of solute carbon content, indicates the difference between the stress of steels at $7.5 \%$ tensile strain and UYS of the steels heated at $100^{\circ} \mathrm{C}$ for $30 \mathrm{~min}$ after $7.5 \%$ straining. As the AI of steel D is zero, the solute carbon content in the steel is considered to be close to zero. Figure 2 shows optical microstructures of the annealed steels. All specimens had polygonal ferrite microstructures. The annealed steels were $20 \%$ cold rolled to introduce plastic strain. The cold-rolled steels were then heat-treated at $50-170^{\circ} \mathrm{C}$ for $0.2-20160 \mathrm{~min}$. The steels were immersed into $\mathrm{pH} 1-\mathrm{HCl}$ for $48 \mathrm{~h}$ in order to introduce hydrogen into the steels. The cold-rolled steels and the heat-treated steels were kept in a freezer until the immersion in $\mathrm{HCl}$. The contents of hydrogen that entered the steels were measured in the same way as described above.

\section{Results}

Figure 3 shows the relationship between immersion time in $\mathrm{HCl}$ and the contents of diffusible hydrogen entering the $0.2 \% \mathrm{C}$ steel (steel A) as-tempered, 10\% cold-rolled and heat-treated at $170^{\circ} \mathrm{C}$ for $20 \mathrm{~min}$ after $10 \%$ cold rolling. The diffusible hydrogen content was substantially saturated after immersion for $24 \mathrm{~h}$ irrespective of the specimens. Hydrogen entry was drastically increased by the cold rolling. As

Table 3. Chemical compositions of steels used (mass $\%$ ).

\begin{tabular}{ccccccccccc}
\hline Steel & $\mathrm{C}$ & $\mathrm{Si}$ & $\mathrm{Mn}$ & $\mathrm{P}$ & $\mathrm{S}$ & $\mathrm{Al}$ & $\mathrm{N}$ & $\mathrm{Ti}$ & $\mathrm{Fe}$ & Free $\mathrm{C}^{*}$ \\
\hline $\mathrm{B}$ & 0.0020 & 0.01 & 1.80 & 0.010 & 0.0013 & 0.032 & 0.0034 & $<0.002$ & Bal. & 0.0020 \\
$\mathrm{C}$ & 0.0028 & 0.01 & 1.83 & 0.010 & 0.0016 & 0.035 & 0.0026 & 0.026 & Bal. & -0.0015 \\
$\mathrm{D}$ & 0.0035 & 0.02 & 1.81 & 0.010 & 0.0012 & 0.035 & 0.0030 & 0.081 & Bal. & -0.0142 \\
\hline
\end{tabular}

*Free carbon content in steel C and steel D: C-(Ti-N*48/14)*12/48

Table 4. Tensile properties of steel B-D.

\begin{tabular}{cccccc}
\hline Steel & UYS (MPa) & LYS (MPa) & TS (MPa) & El (\%) & AI* (MPa) \\
\hline B & 286 & 232 & 327 & 49 & 36 \\
C & 276 & 231 & 342 & 47 & 3 \\
D & 182 & 173 & 348 & 48 & 0 \\
\hline *AI: Aging Index & & &
\end{tabular}



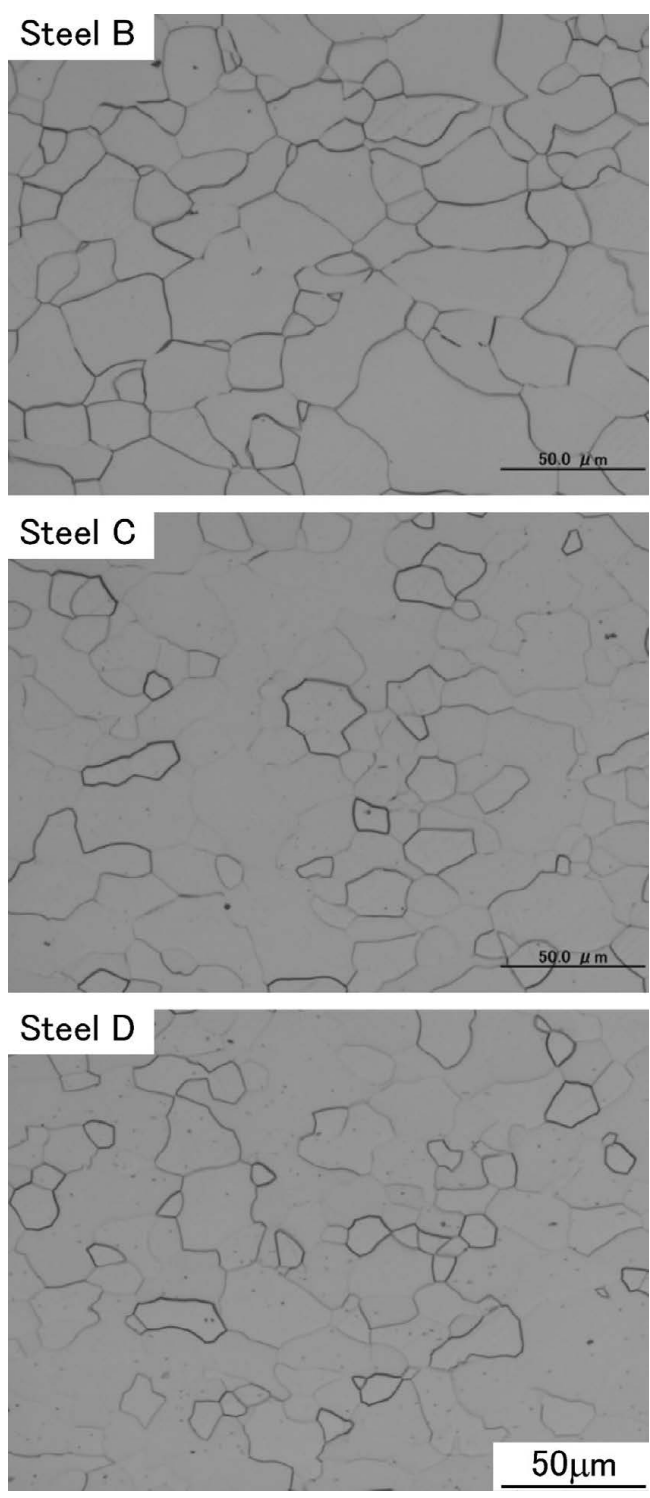

Fig. 2. Optical microstructures of steel B-D.

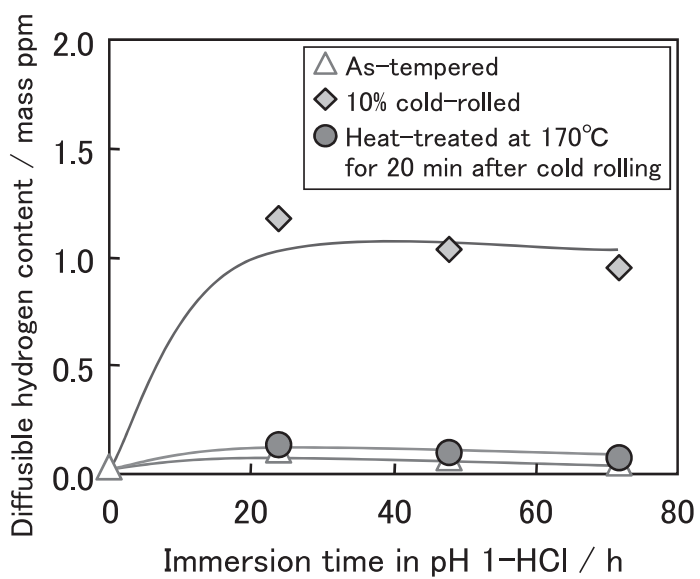

Fig. 3. Effect of cold rolling and heat treatment on the contents of diffusible hydrogen entering specimens (steel A) during immersion in $\mathrm{pH} 1-\mathrm{HCl}$.

reported previously, ${ }^{9,10,13)}$ this increase is attributed to the introduction of hydrogen trapping sites, such as dislocations and vacancies, into the steel by plastic strain. On the other hand, hydrogen entry into the heat-treated steel decreased to

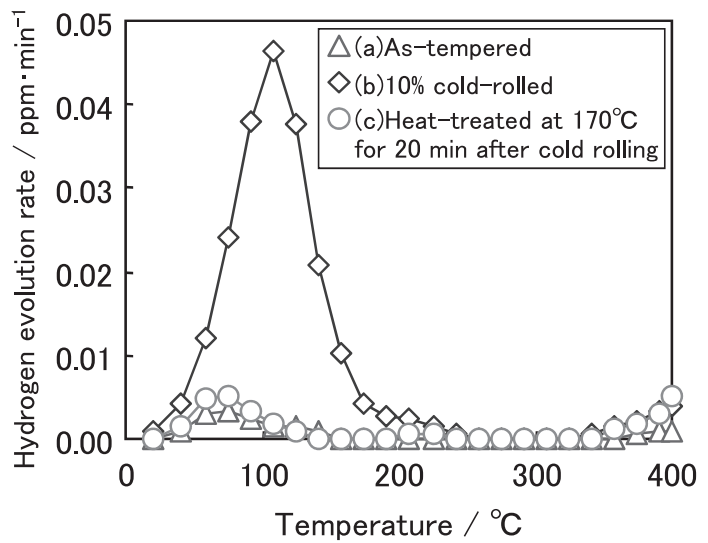

Fig. 4. Hydrogen evolution curves of specimens (steel A) after immersion in $\mathrm{pH} 1-\mathrm{HCl}$ for $48 \mathrm{~h}$. (a)As-tempered, (b) $10 \%$ cold-rolled and (c)Heat-treated at $170^{\circ} \mathrm{C}$ for $20 \mathrm{~min}$ after cold rolling.

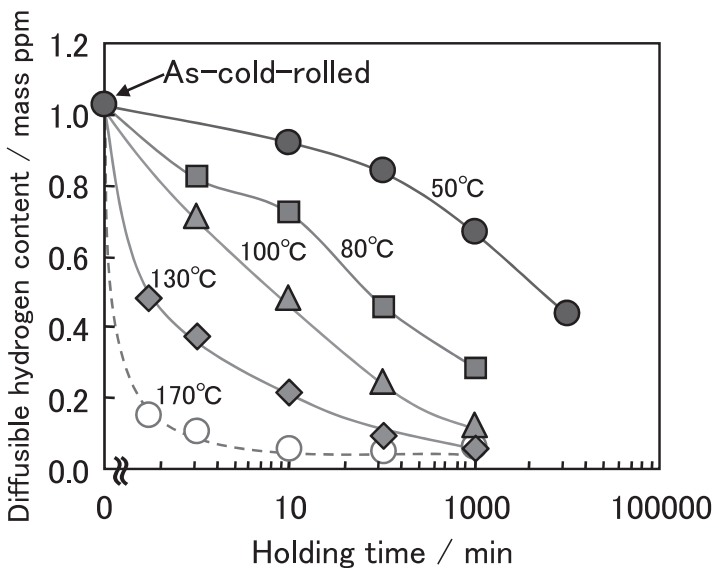

Fig. 5. Influence of heat treatment conditionsafter 10\% cold rolling on the contents of diffusible hydrogen entering specimens(steel A) during immersion in $\mathrm{pH} 1-\mathrm{HCl}$ for $48 \mathrm{~h}$.

the level of the as-tempered steel, which is similar to the result in a previous report. ${ }^{9)}$ Figure 4 shows the hydrogen evolution curves of the specimens in Fig. 3. The immersion time is $48 \mathrm{~h}$. The peak temperature of the cold-rolled specimen was $105^{\circ} \mathrm{C}$, which was higher than that of the undeformed specimen. And the peak temperature of the heattreated specimen was $75^{\circ} \mathrm{C}$, which was the same as that of the undeformed specimen. Therefore, it is suggested that hydrogen trapping sites, which have a relatively higher binding energy with hydrogen, were introduced by the cold rolling, and they disappeared during the heat treatment at $170^{\circ} \mathrm{C}$ after the cold rolling.

Figure 5 shows the influence of the heat treatment conditions after the $10 \%$ cold rolling on the contents of diffusible hydrogen that entered the specimens during immersion in $\mathrm{HCl}$ for $48 \mathrm{~h}$. As the heating temperature and holding time increased, hydrogen entry during immersion in $\mathrm{HCl}$ decreased. From a manufacturing point of view, when evaluating the risk of delayed fracture of steels under service environments, it should be noted that hydrogen entry into steels heat-treated at around $170^{\circ} \mathrm{C}$ for $20 \mathrm{~min}$, which is a typical condition in paint baking treatment, is much lower than that into as-deformed steels. Furthermore, hydrogen entry into the steels was also decreased by the heat treatment at $50^{\circ} \mathrm{C}$, 
which is close to room temperature, for relatively long holding times. This suggests that hydrogen uptake caused by phosphating and electrical painting of auto body parts can also be suppressed by the decrement of hydrogen trapping sites during holding at room temperature after forming.

\section{Discussion}

This section discusses the mechanism of the decrease in hydrogen entry associated with low-temperature heat treatment after deformation, which was described above.

Hydrogen entry under $\mathrm{pH} 1-\mathrm{HCl}$ increased by cold rolling. This means that hydrogen trapping sites were introduced by the cold rolling. Therefore, these hydrogen trapping sites are considered to be related to vacancies and/or dislocations introduced by the cold rolling. These trapping sites were decreased by low-temperature heat treatment below $170^{\circ} \mathrm{C}$ after the cold rolling. This phenomenon could be explained by the following mechanisms: (1) the decrement of dislocations, (2) the decrement of vacancies and (3) the occupation of hydrogen trapping sites around dislocations by interstitial solute atoms such as carbon, which is well known as Cottrell atmosphere.

First, the change in dislocation density due to heat treatment was measured. Figure $\mathbf{6}$ shows the influence of the holding time at $100^{\circ} \mathrm{C}$ after $10 \%$ cold rolling on the dislocation density of the specimens. The dislocation density was not essentially changed by the heat treatment at $100^{\circ} \mathrm{C}$, whereas the content of diffusible hydrogen that entered the steel drastically decreased with the heat treatment at $100^{\circ} \mathrm{C}$ as shown in Fig. 5. Therefore, the change in the dislocation density itself is not the main reason for the decrement of hydrogen trapping sites by low-temperature heat treatment, and this phenomenon is attributed to either the decrement of vacancies or the occupation of hydrogen trapping sites around dislocations by interstitial solute atoms.

Next, the activation energy of the decrement phenomenon of hydrogen trapping sites by the heat treatment was evaluated. Figure 7 shows an Arrhenius plot of the decrement phenomenon of trapping sites shown in Fig. 5. $t_{1 / 2}$ means the holding time when the content of hydrogen entry, which corresponds to the amount of the trapping sites, becomes half that of as-cold-rolled steel at each heating temperature. The activation energy was evaluated by the following

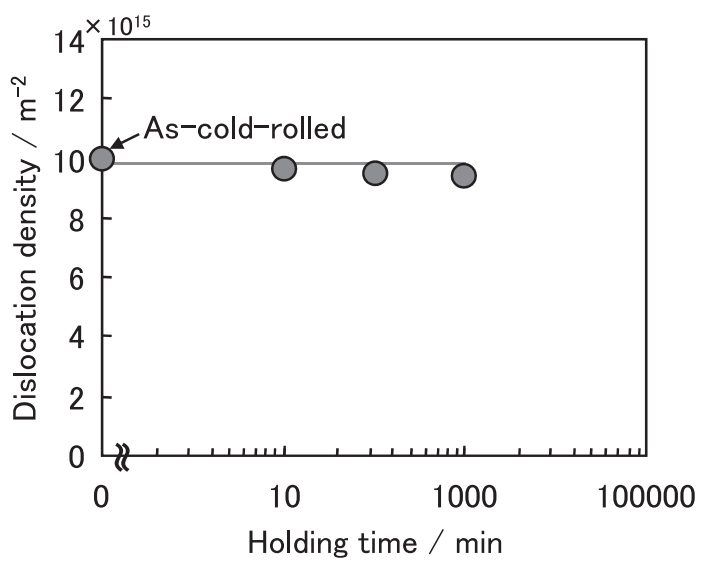

Fig. 6. Influence of holding time at $100{ }^{\circ} \mathrm{C}$ after $10 \%$ cold rolling on dislocation density of steel A. equation:

$$
t_{1 / 2}=A \exp (Q / R T)
$$

where $Q$ is the activation energy, $R$ is the gas constant (8.31 $\mathrm{J} / \mathrm{mol} \cdot \mathrm{K}$ ), $T$ is heating temperature (absolute temperature), and $A$ is a constant. The activation energy, $Q$ is calculated as being about $118 \mathrm{~kJ} / \mathrm{mol}$ from the slope of the graph equal to $Q / R$. This value is slightly larger than the activation energy of the diffusion of a carbon atom in bcc ferrite $(80$ $\mathrm{kJ} / \mathrm{mol}),{ }^{14)}$ and is relatively closed to that of the migration of a vacancy in bec ferrite $\left.(106 \mathrm{~kJ} / \mathrm{mol}) .{ }^{15}\right)$ From this result, the decrement phenomenon of hydrogen trapping sites by the heat treatment might be related to the disappearance of vacancies during the heat treatment.

The binding energy between hydrogen and the trapping sites was also evaluated. Figure 8 shows the hydrogen evolution curves with different heating rate of TDA from $50^{\circ} \mathrm{C} / \mathrm{h}$ to $200^{\circ} \mathrm{C} / \mathrm{h}$ of as-cold-rolled specimen (steel A) immersed in $\mathrm{pH} 1-\mathrm{HCl}$ for $48 \mathrm{~h}$. The peak temperature shifted to a lower temperature as the heating rate decreased. The activation energy of the escape reaction of hydrogen from a trapping site was evaluated by the following equation: ${ }^{16)}$

$$
E a \Phi / R T^{2}=B \exp (-E a / R T) \ldots
$$

where $E a$ is the activation energy, $\Phi$ is the heating rate, $R$

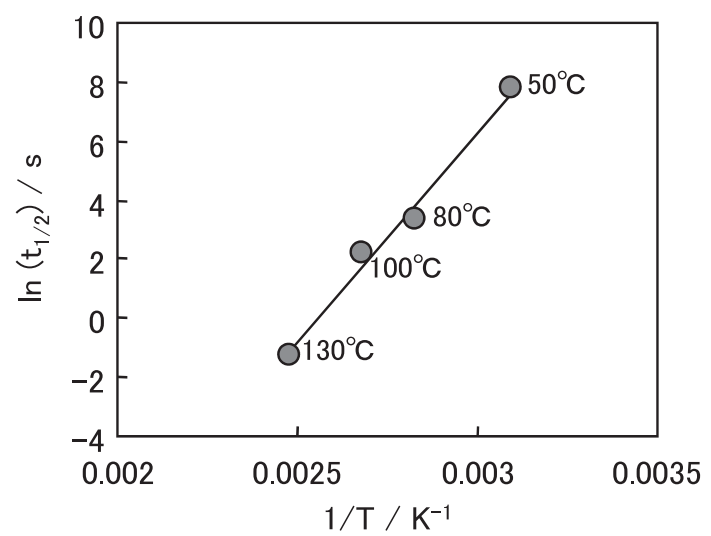

Fig. 7. Arrhenius plot of the decrement phenomenon of hydrogen trapping sites shown in Fig. 5. T: heating temperature (absolute temperature), $\mathrm{t}_{1 / 2}$ : holding time when the content of hydrogen entry becomes half that of as-cold-rolled steel at each heating temperature.

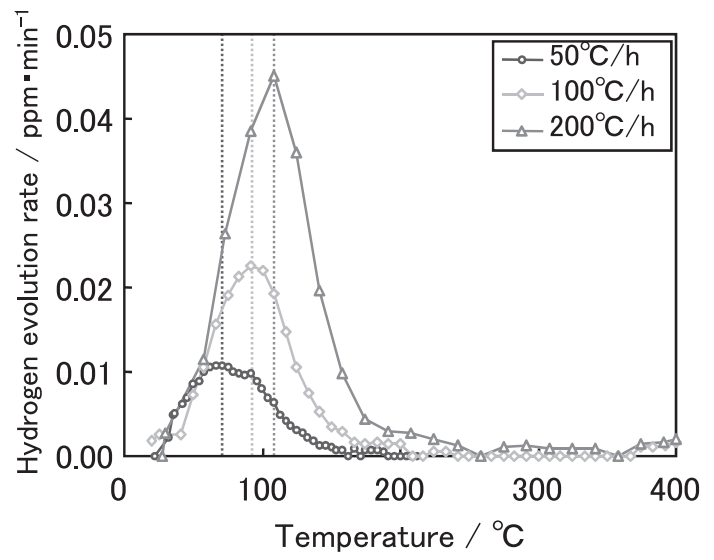

Fig. 8. Effect of heating rate on hydrogen evolution curve of $10 \%$ cold-rolled specimen (steel A) immersed in $\mathrm{pH} \mathrm{1-HCl} \mathrm{for} 48 \mathrm{~h}$. 
is the gas constant $(8.31 \mathrm{~J} / \mathrm{mol} \cdot \mathrm{K}), T$ is the peak temperature (absolute temperature) of the hydrogen evolution curve, and $B$ is a constant. Figure 9 shows the relationship between $\ln \left(\Phi / T^{2}\right)$ and $1 / \mathrm{T}$. The activation energy, $E a$ is calculated as being $29.2 \mathrm{~kJ} / \mathrm{mol}$ from the slope of the graph equal to $E a / R$. Figure 10 shows a schematic diagram of a hydrogen trapping site. The activation energy of the escape reaction of hydrogen from a trapping site, $E a$ is the summation of the diffusion activation energy of hydrogen in normal lattice (En) and the binding energy between a trapping site and hydrogen $(\mathrm{Eb}){ }^{16)} \mathrm{En}$ is reported as being $7.6 \mathrm{~kJ} / \mathrm{mol}^{17}{ }^{17}$ Therefore, the binding energy between hydrogen and the trapping site is calculated to be $21.6 \mathrm{~kJ} / \mathrm{mol}$. This value is close to the reported value of the binding energy between hydrogen and a dislocation (around $20 \mathrm{~kJ} / \mathrm{mol}$ ), ${ }^{18-20}$ ) but is much smaller than that between hydrogen and a vacancy (around $50 \mathrm{~kJ} / \mathrm{mol}$ ). ${ }^{21,22)}$ According to this result, the hydrogen trapping sites in the cold-rolled steel might be related to dislocation, that is, the decrement of trapping sites by low-temperature heat treatment is attributed to the occupation of hydrogen trapping sites around dislocations by interstitial solute atoms (Cottrell atmosphere).

Activation energies of the reactions, which are related to the hydrogen trapping site, evaluated by above two methods reached the different results. This may be because several phenomena occurred at the same time during heat treatment of the cold-rolled steel, or the hydrogen evolution peak in TDA contained the peaks related to both dislocation and vacancy; hence it was difficult to separate the contribution of dislocation and vacancy. In order to separate the contribution of the decrement of vacancies and Cottrell atmosphere, the influence of solute carbon content on this phe-

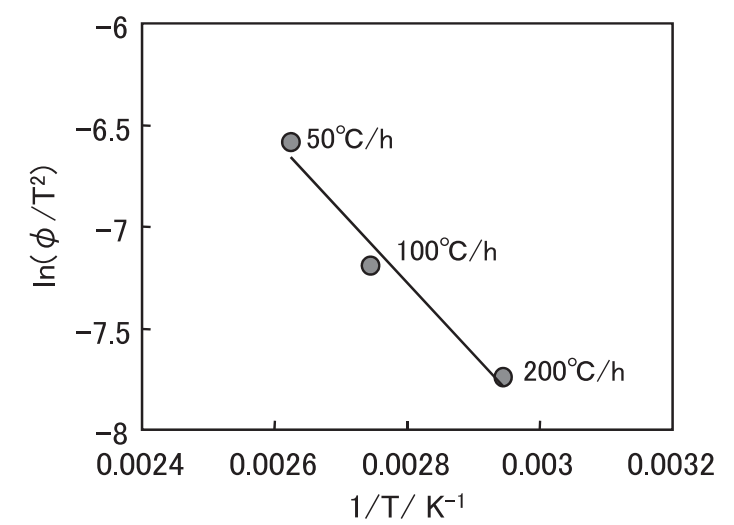

Fig. 9. Relationship between $1 / \mathrm{T}$ and $\ln \left(\Phi / \mathrm{T}^{2}\right)$. $\mathrm{T}$ : peak temperature (absolute temperature) at each heating rate, $\Phi$ : heating rate of TDA.

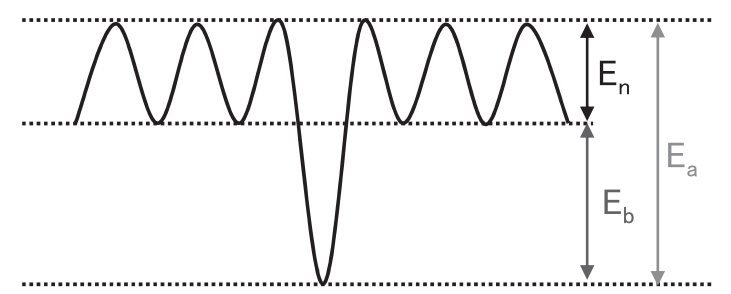

Fig. 10. Schematic diagram of a hydrogen trapping site. En: diffusion activation energy of hydrogen in normal lattice, Eb: binding energy between trapping site and hydrogen, Ea: trap activation energy. nomenon was then investigated using low carbon and ultralow carbon steels listed in Table 3 .

Figure 11 shows the influence of the Ti content in the

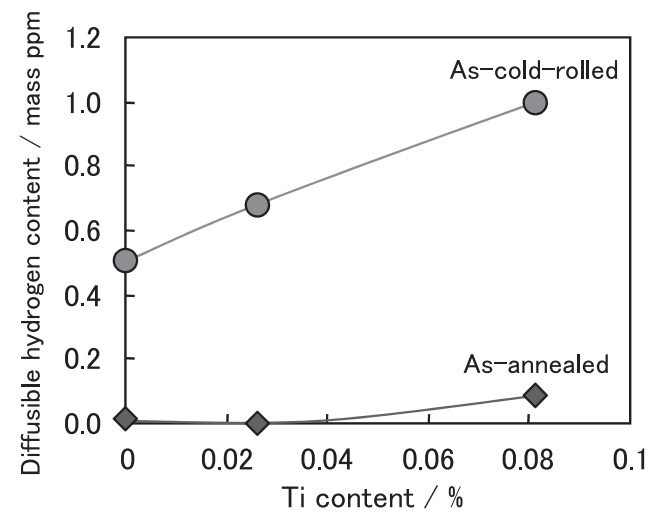

Fig. 11. Influence of Ti content in the steels on the contents of diffusible hydrogen that entered as-annealed and as-coldrolled specimens (steel B-D) during immersion in $\mathrm{pH}$ 1$\mathrm{HCl}$ for $48 \mathrm{~h}$.
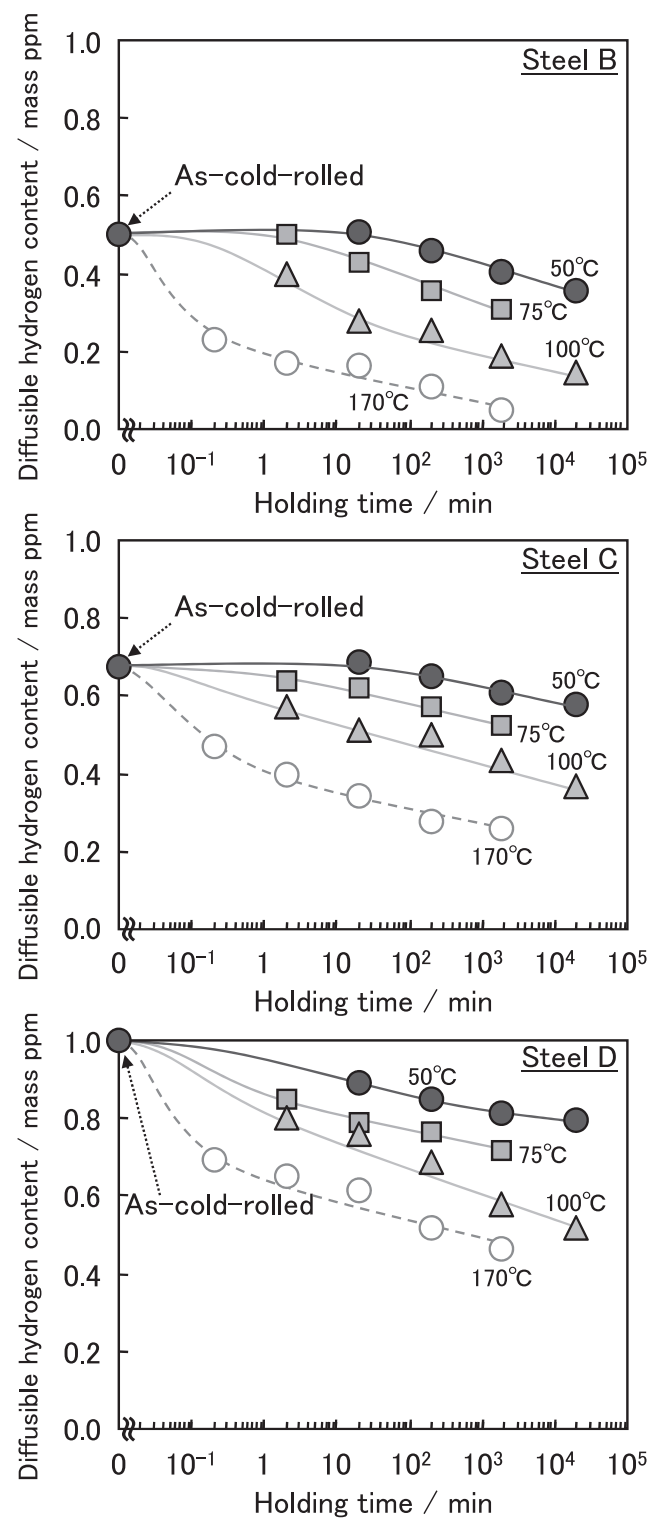

Fig. 12. Influence of heat treatment conditions after $20 \%$ cold rolling on the contents of diffusible hydrogen entering specimens (steel B-D) during immersion in $\mathrm{pH} 1-\mathrm{HCl}$ for $48 \mathrm{~h}$. 
steels on the contents of diffusible hydrogen that entered asannealed and as-cold-rolled steels during immersion in $\mathrm{pH}$ $1-\mathrm{HCl}$ for $48 \mathrm{~h}$. The contents of hydrogen that entered asannealed steels and 20\% cold-rolled steels increased with the Ti content. This increase in hydrogen entry into asannealed steels and 20\% cold-rolled steels with the Ti content is attributed to titanium carbides and defects (dislocations and/or vacancies) induced by the titanium carbides during cold rolling, respectively. Figure 12 shows the influence of heat treatment conditions after $20 \%$ cold rolling on the content of diffusible hydrogen that entered the steel B$\mathrm{D}$ during immersion in $\mathrm{pH} 1-\mathrm{HCl}$ for $48 \mathrm{~h}$. Same as the results of the steel A (Fig. 5), as the heating temperature and holding time increased, hydrogen entry during immersion in $\mathrm{HCl}$ decreased irrespective of the steels with or without solute carbon atoms. Figure $\mathbf{1 3}$ shows the influence of the holding time at $100^{\circ} \mathrm{C}$ and $170^{\circ} \mathrm{C}$ after $20 \%$ cold rolling on the dislocation density of the steel $\mathrm{B}$ and $\mathrm{D}$. The dislocation density was not essentially changed by the heat treatment, same as the result of the steel A (Fig. 6). From these results, in the case of $0.08 \% \mathrm{Ti}$ steel, which is considered to contain no solute carbon atoms, the main reason for the decrement of hydrogen entry, that is, the decrement of hydrogen trapping sites, with the heat treatment could be the decrease in vacancies. However, compared with the steel without $\mathrm{Ti}$ (steel B), which contains solute carbon atoms, the decrement ratio from the content of hydrogen that entered ascold-rolled specimen seems to be different. To make a relative comparison of the decrement ratio of trapping sites, which were introduced by cold rolling, among these steels with different hydrogen trapping ability, $\mathrm{H}^{*}$ for each steel was defined as the following equation:
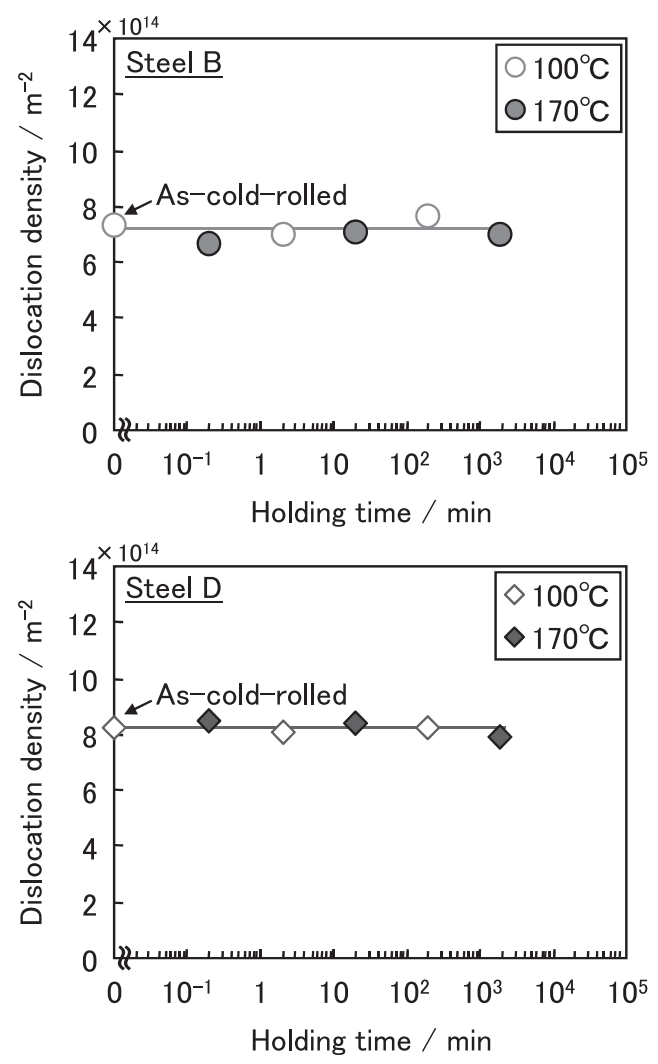

Fig. 13. Influence of holding time at $100-170^{\circ} \mathrm{C}$ after $20 \%$ cold rolling on dislocation density of steel $\mathrm{B}$ and steel $\mathrm{D}$.

$$
H^{*}=\left(H-H_{a}\right) /\left(H_{c}-H_{a}\right)
$$

where $H$ is the content of hydrogen entering each specimen, $H_{a}$ is the content of hydrogen entering the as-annealed specimen, which is not related to the trapping sites introduced by cold rolling, and $H_{c}$ is the content of hydrogen entering the as-cold-rolled specimen. Figure 14 shows the change in $H^{*}$ with heat treatment for each steel. The decrement ratio of trapping sites in the $0.08 \% \mathrm{Ti}$ steel (steel D) was about half that in the $0 \% \mathrm{Ti}$ steel (steel B). Figure 15 shows the influence of free carbon content on the maximum decrement ratio of hydrogen entry $\left(1-\mathrm{H}^{*}\right.$ min $)$ due to heat treatment within the experimental conditions in this research. When the free carbon content is below zero, the change in the maximum decrement ratio with free carbon content was small. On the other hand, in the case that the free carbon atoms exist, the maximum decrement ratio of hydrogen entry was bigger than the case without free carbon atoms. Therefore, in the steel containing solute carbon atoms, not only the
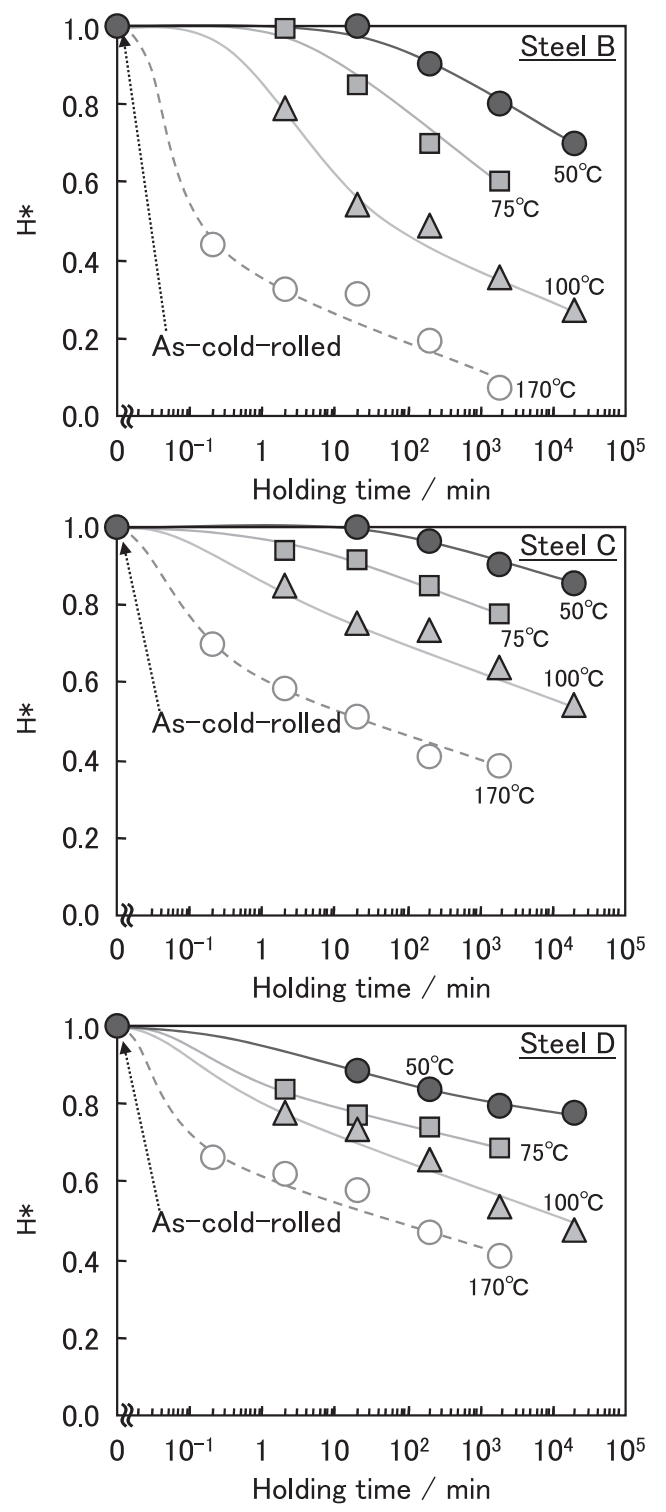

Fig. 14. Change in $\mathrm{H}^{*}$ with heat treatment for steel B-D. $\mathrm{H}^{*}=$ Amount of diffusible hydrogen entering each specimen/Amount of diffusible hydrogen entering 20\% coldrolled specimen for each steel. 


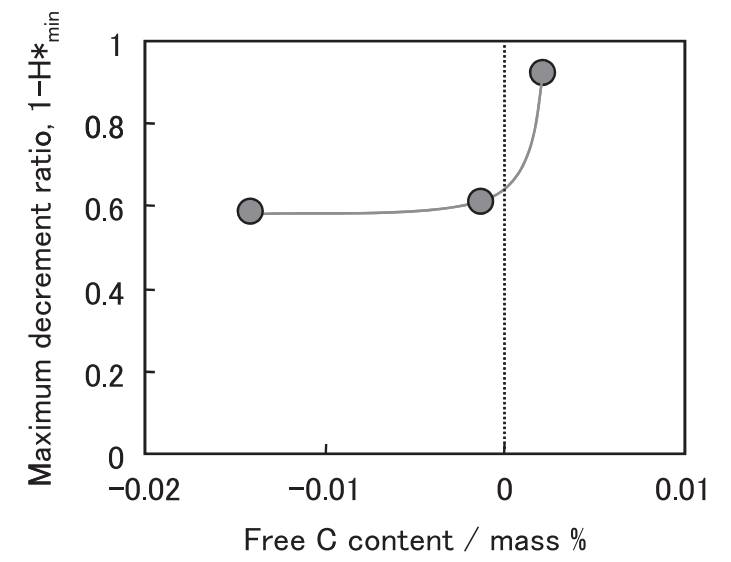

Fig. 15. Effect of free carbon content on the maximum decrement ratio $\left(1-\mathrm{H}^{*}{ }_{\min }\right)$ within the experimental conditions in this research.

decrease of vacancies but also the occupation of hydrogen trapping sites around dislocations by solute carbon atoms could have a large influence on hydrogen entry.

Phenomena similar to the results of this research have also been reported by Hagi et al., ${ }^{23)}$ who investigated the change in the diffusion coefficient of hydrogen with heating by means of the hydrogen permeation test, using two kinds of $9 \%$ cold-rolled steels containing different levels of interstitial solute atoms. The diffusion coefficient of hydrogen increased with increasing heating temperature (below $250^{\circ} \mathrm{C}$ ) in the steel with a high content of interstitial solute atoms, but showed little change in the steel with fewer interstitial solute atoms. They proposed that the formation of an atmosphere of interstitial impurity atoms $(\mathrm{C}, \mathrm{N})$ around dislocations weakened the hydrogen trapping effect of the dislocations. Abe et al. $^{24)}$ also reported that solute carbon atoms weakened the interaction between hydrogen atoms and dislocations. From their results and the present results in this paper, it is quite possible that solute carbon atoms affect the trapping phenomena of hydrogen.

Therefore, in the case of ultra-high strength steel sheets, which generally contain solute carbon atoms, not only the decrement of vacancies but also the occupation of hydrogen trapping sites around dislocations by interstitial solute atoms such as carbon could have a large influence on the decrement of hydrogen entry by low-temperature heat treatments after forming.

\section{Conclusions}

The influence of temperature and holding time in lowtemperature heat treatment after deformation on hydrogen entry into steel sheets was investigated in detail, and the mechanism of the decrement of hydrogen entry by the heat treatment was also discussed. The results obtained in this study are summarized as follows:

(1) Hydrogen entry into steel during immersion in $\mathrm{pH}$ 1-HCl increased with deformation and decreased with the following low-temperature heat treatment below $170^{\circ} \mathrm{C}$, and as the heating temperature and holding time increased, hydrogen entry during immersion in $\mathrm{HCl}$ decreased.

(2) From a comparison of steels with and without solute carbon atoms, the decrement of hydrogen entry due to the lowtemperature heat treatment was attributed to both the decrement of vacancies and occupation of hydrogen trapping sites around dislocations by interstitial solute atoms such as carbon.

\section{REFERENCES}

1) S. Matsuoka, K. Hasegawa and Y. Tanaka: JFE Tech. Rep., 10 (2007), 13.

2) Y. Toji, K. Hasegawa, H. Shigemoto, H. Kawabe, T. Fujita, Y. Tanaka, H. Nakamura, H. Ishida and H. Sakamoto: Rev. Automotive Eng., 30 (2009), 159.

3) S. Matsuyama: Delayed Fracture, The Nikkan Kogyo Shimbun LTD., Tokyo, (1989)

4) Y. Toji, S. Takagi, M. Yoshino, K. Hasegawa and Y. Tanaka: Tetsuto-Hagané, 95 (2009), 887.

5) Y. Toji, S. Takagi, M. Yoshino, K. Hasegawa and Y. Tanaka: Mater. Sci. Forum, 638-642 (2010), 3537.

6) T. Kushida, H. Matsumoto, N. Kuratomi, T. Tsumura, F. Nakasato and T. Kudo: Tetsu-to-Hagané, 82 (1996), 297.

7) S. Yamasaki and T. Takahashi: Tetsu-to-Hagané, 83 (1997), 454.

8) Y. Hagihara, C. Ito, N. Hisamori, H. Suzuki, K. Takai and E. Akiyama: Tetsu-to-Hagané, 94 (2008), 215.

9) M. Nagumo and H. Matsuda: Philos. Mag. A, 82 (2002), 3415.

10) Y. Toji, S. Takagi, M. Yoshino, K. Hasegawa and Y. Tanaka: CAMPISIJ, 21 (2008), 1453, CD-ROM

11) G. K. Williamson and W. H. Hall: Acta Metall., 1 (1953), 22.

12) G. K. Williamson and R. E. Smallman: Philos. Mag., 8 (1956), 34.

13) K. Takai, H. Shoda, H. Suzuki and M. Nagumo: Acta Mater., 56 (2008), 5158.

14) W. Pascheto and G. P. Johari: Metall. Mater. Trans. A, 27A (1996), 2461 .

15) K. Sugimoto, K. Osamura, T. Yamane, T. Maki, S. Kikuchi, S. Ochiai and Y. Murakami: Zairyo-Soshikigaku, Vol. 11, Asakura Shoten, Tokyo, (1997), 75

16) W. Y. Choo and J. Y. Lee: J. Mater. Sci., 17 (1982), 1930.

17) O. D. Gonzalez: Trans. TMS-AIME, 245 (1967), 607

18) C. M. Sturges and A. P. Miodownik: Acta Metall., 17 (1969), 1197.

19) S. Asano and N. Shibata: Scr. Metall., 16 (1982), 1171.

20) R. A. Oriani: Acta Metall., 18 (1970), 147.

21) S. M. Myers, S. T. Picraux and R. E. Stoltz: J. Appl. Phys., 50 (1979), 5710 .

22) S. M. Myers, D. M. Follstaedt, F. Besenbacher and J. Bøttiger: J. Appl. Phys., 53 (1982), 8734.

23) H. Hagi and Y. Hayashi: J. Jpn. Inst. Met., 51 (1987), 24.

24) N. Abe, H. Suzuki, K. Takai, Y. Hagihara, H. Sueyoshi and N. Ishikawa: CAMP-ISIJ, 23 (2010), 368, CD-ROM. 